Resenha 


\title{
REFLEXÕES SOBRE UMA DAS OBRAS DE SVETLANA ALEKSIÉVITCH: AS MEMÓRIAS DAS CRIANÇAS QUE SOBREVIVERAM A SEGUNDA GUERRA MUNDIAL
}

\author{
Reflection About One of the Works by Svetlana Aleksiévitch: The \\ Memomries of Children Who Survived the Second World War
}

\author{
Pauline Iglesias Vargas \\ Maria Eloisa de Oliveira ${ }^{2}$
}

\begin{abstract}
RESUMO
A presente resenha versa criticamente sobre a obra "As últimas testemunhas: crianças na Segunda Guerra Mundial". Trata-se de um livro originalmente escrito em russo de caráter literário/comercial com autoria de Svetlana Aleksivitch. A obra é resultado de cerca de cem entrevistas de sobreviventes da Segunda Guerra que a rememoram de forma singular, afinal, eram "apenas crianças na época". As reflexões do passado são realizadas por sujeitos do presente, via de regra, esta demanda de narrativa está marcada pelo trauma. Contudo, se por um lado a escrita simples desperta o interesse e facilita a compreensão e a interpretação do significado da Segunda Guerra para as crianças; por outro, não se tem um detalhamento do procedimento metodológico para se chegar documento escrito.
\end{abstract}

Palavras-chave: Literatura; Memória; História Oral.

\begin{abstract}
This review deals critically with the work "The Last Witnesses: Children in World War II". It is a book originally written in Russian with a literary / commercial character by Svetlana Aleksivitch. The book is the result of about one hundred interviews of survivors of World War II who remember it in a unique way; after all they were "just children at the time". The reflections of the past are carried out by subjects of the present, as a rule, this demand for narrative is marked by the trauma. However, if on the one hand simple writing arouses interest and facilitates the understanding and interpretation of the meaning of the Second War for children; on the other hand, there is no detail of the methodological procedure for arriving at a written document.
\end{abstract}

Keywords: Literature; Memory; Oral History;

1 Licenciada, Mestre e Doutoranda em Educação Física pela Universidade Federal do Paraná. Tem experiência na área de Educação Física, com ênfase em Ginástica Rítmica e Inclusão. Atualmente é professora de ensino superior da Universidade Positivo. E-mail: piglesiasvargas@gmail.com. ORCID: https://orcid.org/0000-0002-6756-4674.

2 É graduanda do curso de Educação Física Licenciatura da Universidade Positivo. E-mail: meo.medo2000@gmail.com. ORCID: https://orcid.org/0000-0002-8601-0108. 


\section{Introdução}

A obra intitulada "As Últimas Testemunhas: crianças na Segunda Guerra Mundial" trata-se de um livro traduzido do russo em sua $1^{\circ}$ edição no ano de 2018 , pela editora Schwarcz S.A, São Paulo e publicado pela Companhia das Letras. A autora, Svetla Aleksivitch, jornalista, nasceu em 1948, na Ucrânia, dedicando a sua vida literária/profissional de forma única à observação, escuta e transcrição de relatos a respeito de momentos factuais da história. Momentos dos quais teve forte vínculo afetivo: após a desmobilização de seu pai do exército, a família retornou à sua cidade natal, na Bielorrússia. Aleksievich, estudou na Universidade de Minsk, entre 1967 e 1972. Por causa de sua crítica ao regime, viveu periodicamente no exterior. Em 2015, recebeu o prêmio Nobel de literatura, mesmo escrevendo originalmente em língua russa. Desde então, algumas de suas obras emblemáticas: "Vozes de Tchernóbil (2016)", "A Guerra Não Tem Rosto de Mulher (2016)", "Fim do Homem Soviético (2016)" e o mais atual "Meninos de Zinco (2020)" passaram a ser traduzidas para diversas línguas, dentre elas o português (THE NOBEL PRIZE, 2015).

A obra em questão é o resultado de um trabalho com cerca de cem entrevistas realizadas entre os anos de 1978 e 2004. O que esses adultos tinham em comum? Sobreviventes, com memórias do horror da Segunda Guerra Mundial, afinal, eram "apenas crianças". Particularmente, crianças são afetadas de maneiras diferentes na Guerra. Fisicamente: quando há falta de comida ou água. Psicologicamente: quando expostas a grandes cenas de horror da guerra, como bombardeios, brigas e deixar suas próprias casas. Emocionalmente: quando pode estar diretamente na guerra, como membro servindo, ou tendo outra ocupação nas forças (MOCHMANN, 2008).

O método utilizado por Svetlana Alexievich merece destaque. A autora expõe com fidedignidade as vozes das crianças daquela época, a partir da visão de mundo do adulto/idoso no "tempo presente". O que ela define como uma história oral, sincera, autêntica e arrebatadora. Importante ressaltar que as fontes orais e escritas (documentais) não são excludentes. Desta forma, apenas necessitam de instrumentos interpretativos diferentes e específicos. A transcrição nesse sentido, transforma objetos auditivos em visuais dando aspectos de determinado grupo social (PORTELI, 1997). Outro ponto que exacerba da obra é a relação entre a História e a Literatura, confluência que amadurece com a utilização da história oral e a sua consequente amplitude como fonte histórica (NAPOLITANO, 2020).

No livro, a criança é quem se sobressai com nome e participação direta em meio a relatos sutis e papéis ativos. A memória, contudo, deve ser entendida como uma manifestação coletiva e social, ou seja, como um fenômeno construído coletivamente e submetido a flutuações, transformações e mudanças constantes. Como Pollak (1992, p. 13) ressalta: "Não é natural uma pessoa falar sobre si”. Nas narrativas foi possível observar a utilização do pronome "nós", os personagens reafirmam a identidade como pertencente ao grupo pesquisado: “[...] Nós, as crianças, vigiávamos as caixas de garrafa com líquido inflamável, trouxemos areia e água para caso de um incêndio [...]" (p. 41). Em outros trechos, o predomínio de determinados pronomes pessoais, no conjunto de um relato de vida seria uma medida ou um indicador, do grau de segurança interna da pessoa (POLLAK, 1992), observado em: “[...] Por acaso éramos crianças? Com dez, onze anos éramos homens e mulheres [...]" (p. 249).

A memória dos adultos, ainda de um tempo em que eram crianças, toma o lugar de protagonista. Um dos entrevistados afirmou: “[...] A memória tem cor [...]" (p. 250). As 
lembranças se sobressaem de forma monocromática, provavelmente por conta do episódio traumatizante, e mascaram as memórias: “[...] Não tenho certeza se de fato tudo isso era só preto, mas é assim que me lembro. Um filme em preto e branco. [...]" (p. 28). Outro, retrata uma vida com cor, anterior ao início da Guerra: “[...] Ficou na minha memória uma cor. Depois todas as lembranças tem cor escura [...]" (p. 44). Indo de encontro a estudos que reforçam: "A memória é seletiva. Nem tudo fica gravado. Nem tudo fica registrado." (POLLAK, 1992, p.4).

Desta forma, a obra aparenta contemplar narradores cujas consciências parecem ter sido capturadas em momentos de suas experiências pessoais mais marcantes, como no caso, aqueles episódios ocorridos durante a Segunda Guerra Mundial. O que acontece é que: "[...] frequentemente, estes indivíduos são absorvidos integralmente pela totalidade do evento histórico no qual participaram e seus relatos apresentam cadências e fraseologia épicas." (PORTELI, 1997, p. 34). Essas narrativas estão marcadas pelo trauma e ao serem relembradas por sujeitos do presente, limitam a objetividade como representação do passado (NAPOLITANO, 2020), reafirmada em: “[...] Algo aconteceu com a minha memória. Não me lembro dos rostos, não me lembro das palavras [...]” (p. 64). Nesses casos, a informação mais preciosa está no que os informantes relataram, e porque relataram, utilizando de mais (ou menos) palavras (PORTELI, 1997).

As narrativas aguçam o leitor ao retomar as infâncias, sendo assim, são a mostra viva de um processo histórico e uma marcante função da memória. Levanta-se a questão: o que fica guardado na memória? Na maioria das memórias existem marcos ou pontos relativamente invariantes e imutáveis (POLLAK, 1992), assim como no exemplo: “[...] Uma criança de três anos consegue guardar algo? "Vou responder... Guardei três ou quatro cenas com absoluta nitidez [...]" (p. 202). Ainda assim, é possível interpretar a partir das lacunas, como em: "[...] E aí eu tenho uma lacuna na memória [...]" (p. 54). Essas, quando interpretadas devem ser vistas como possibilidade, e não "falhas na memória". Conforme indica Thompson (1992), o importante é compreender aquilo que não está sendo dito e aprender ao considerar o que significam os silêncios.

Aautora transcreve trechos nos quais resquícios do imaginário infantil foram identificados na escuta dos entrevistados. Os relatos mostram os brinquedos como elementos dificilmente encontrados no período da infância: "[...] Durante a guerra eu não tinha visto nenhum objeto infantil. Havia esquecido que eles existiam em algum lugar. Os brinquedos de criança [...].” (p. 43). Os entrevistados mencionam como queriam levar broncas, brigar por brinquedos, sentiam falta da infância, saudade da "alegria infantil". Dificultando uma identidade de criança na percepção delas mesmas: "[...] Como queria brinquedos de criança! Queria ser criança [...]" (p. 172). Pode-se entender tanto individual como coletiva a importância desse sentimento de coerência em um grupo, no caso, a tentativa de reconstrução da infância. Dessa forma, apresenta-se a memória como sentimento de identidade (POLLAK, 1992).

Os personagens parecem tentar manter as memórias vivas: “[...] É uma questão... O que é melhor? Lembrar ou esquecer? Será melhor ficar calado? Levei muitos anos para esquecer [...]" (p. 81). Conforme afirma Portelli (1997), fontes orais contam não apenas o que o povo fez, mas o que queria fazer, o que acreditava estar fazendo e o que agora pensa que faz. Confirmando a ideia do autor, o trecho do depoimento que traz: "[...] Me recordo da guerra para compreender... Se não para que? [...]" (p. 116). É preciso, contudo, ir além da história do acontecimento, interessando-se também pela história da memória desse acontecimento.

Alesiévitch não interrompe os relatos com análises extensas, a participação da autora 
é mínima, com apenas uma tentativa de epílogo e um prefácio sucinto escritos por ela na primeira pessoa. O seu distanciamento fica evidente nos títulos que separam os depoimentos no livro. Tais títulos não apresentam sua contribuição (são trechos dos relatos dos próprios pesquisados), mas, ainda assim, a própria escolha do trecho mostra a sua participação e seus ideais com a obra. A pesquisadora é um resíduo de uma ação interativa, a comunicação com o entrevistado (ALBERTI, 1996). Sendo que, para alcançá-las, é preciso manter um longo diálogo interpessoal muito cuidadoso, próximo e íntimo. É a partir de seus interesses que reordena os acontecimentos rememorados pelos entrevistados, considerando que cada vida corresponde a um fluxo de lembranças. Assim, mesmo que o entrevistador fale pouco, para permitir ao entrevistado narrar suas experiências, a entrevista que ele conduz é parte de seu próprio relato, no caso, literário, sobre ações passadas (ALBERTI, 1996).

A obra remete ao papel do entrevistador ao recordar memórias duras, esse trata de um processo de percepção variável e individual de acordo com a relevância que o entrevistado atribui ao ocorrido até o momento que é relembrado (THOMPSON, 1992). O limite da memória destaca-se em algumas frases: "[...] Para que fui lhe contar isso? Agora estou pior do que antes. É por isso que não me recordo [...]” (p. 78). Até mesmo a possibilidade de interrupção do relato, contemplando a necessidade do pesquisado é apresentada: "[...] Chega basta estou muito abalado [...]" (p. 88).

Em meio às frases dos entrevistados é possível observar a dificuldade da inserção desses personagens na sociedade, no pós guerra: “[...] Você não tem medo de mim? De me ouvir [...]" (p. 125). Passaram muitos anos até conseguirem contar uns aos outros sobre guerra, questionamse quanto tempo seria necessário para esquecer, afinal, tudo isso faz parte do tenso relato: "[...] Contei para você alguns dias. Mas foram novecentos [...]" (p. 245). Estas oscilações são significativas. Apoiar-se em um episódio pode ser um caminho a salientar sua importância, e/ ou uma estratégia para desviar a atenção de outros pontos mais delicados (PORTELI, 1997).

A escrita da obra apresenta uma linguagem simples e pragmática, facilitando a compreensão das possibilidades de utilização do método abordado. Se por um lado a escrita simples desperta o interesse e facilita a interpretação do significado da Segunda Guerra para as crianças, por outro, não se tem um detalhamento do procedimento metodológico para se chegar documento escrito. Seriam as entrevistas transcritas na íntegra? As narrativas passaram por algum tipo de tratamento e edição? - conforme indica Alberti (1996). De que forma a autora chegou aos entrevistados? Quais os critérios objetivos de inclusão e exclusão? Qual foi o ambiente da realização das entrevistas? Também carecem de detalhamento, deixando ao leitor a possibilidade de apenas de pressupor ou especular, dificultando a reprodução do método em futuras pesquisas, que venham a trabalhar com aspectos da memória e a história oral aplicados a outros temas. Por isso, julga-se relevante compreender como se deu esse processo dialógico.

Nas últimas páginas da obra, o relato emerge com a frase que dá título à obra sendo elucidada, em uma única voz em tom de apelo: “[...] Somos as últimas testemunhas. Nosso tempo está acabando. Devemos falar... nossas palavras serão as últimas [...]” (p. 269). Trazendo as narrativas como uma fonte histórica que revela não só as palavras, mas os significados que insuflam vida na história. Especialmente, enriquecem a sociedade com uma contribuição modificada do campo social inserido e a sua mensagem, legitimando-a de forma mais democrática. Afinal, "[...] nos quinze anos posteriores ao término da Segunda Guerra Mundial, a ênfase na reconstrução nacional dos países, incluindo os próprios vencedores do conflito, não deu muito espaço à memória dolorosa dos sobreviventes [...]" (NAPOLITANO, 2020 p.27). 
A obra de Alesiévitch simboliza o uso da história oral como meio de conhecimento, não sendo um fim em si mesma (THOMPSON, 1992), a partir de um olhar sensível desenvolvido com primazia. Quando alguém escreve uma obra de caráter histórico e atinge com respeito ao grande público, está cumprindo também, um papel com valor social imprescindível, o despertar a cidadania e o respeito à diferença.

\section{Referências}

ALBERTI, Verena. O que documenta a fonte oral? Possibilidades para além da construção do passado. 1996. Disponível em: https:/bibliotecadigital.fgv.br/dspace/bitstream/handle/10438/6767/869.pdf.Acesso em: $30 / 03 / 2020$.

ALEKSIÉVITCH, Svetlana. As últimas testemunhas: crianças na Segunda Guerra Mundial. São Paulo: Companhia das Letras, 2018.

MOCHMANN, Ingvill C. Children Born of War. OBETS: Revista de Ciencias Sociales. Espanha, n. 2, p. 53-61, 2008.

NAPOLITANO, Marcos. Desafios para a História nas encruzilhadas da memória: entre traumas e tabus. História: Questões \& Debates, Curitiba, v. 68, n. 01, p. 18-56, jan./jun., 2019.

PORTELLI, Alessandro. O que faz a história oral diferente. Projeto História: Revista do Programa de Estudos Pós-Graduados de História. v.14, 1997.

POLLAK, Michel. Memória e identidade social. Estudos Históricos. Rio de Janeiro, CPDOC-FGV, v.5, n.10, p.200-215, 1992.

Svetlana Aleksiévich - Biographical. THE NOBEL PRIZES 2015. The Nobel Foundation by Science History Publications/USA, division Watson Publishing International LLC, Sagamore Beach, 2016. Disponível em: https:// www.nobelprize.org/prizes/literature/2015/alexievich/biographical/ Acesso em: 30/03/2020.

THOMPSON, Paul. História oral: a voz do passado. Rio de Janeiro: Paz e Terra, 1992.

RECEBIDO EM: 31/03/2020

APROVADO EM: 09/04/2020 